\title{
¿«PER VILTÀ»O «PER VALENTIA»? \\ DANTE ALIGHIERI ACTUALIZADO POR \\ CONSTANTINO CAVAFIS Y \\ MIGUEL DE UNAMUNO
}

\author{
Styliani Voutsa \\ Universidad Aristóteles de Tesalónica, Grecia
}

Resumen: El estudio se centra en la lectura personal que hicieron de un pasaje dantesco el poeta griego C. Cavafis en su poema «Che fece... il gran rifiuto» (1901) y el español M. de Unamuno en «La gran rehusa» (1910). Dichas composiciones se analizan en un primer momento por separado, poniendo el acento, sobre todo, en la repercusión que tuvieron ambas en la crítica literaria. En segundo lugar, los dos poemas se examinan de manera comparada.

Palabras clave: Cavafis - Unamuno - Dante

«For cowardliness» or «for bravery»?

Dante Alighieri updated by

\section{Constantino Cavafis and Miguel de Unamuno}

\begin{abstract}
The study focuses on the personal lecture that the Greek poet C. Cavafis and the Spanish poet M. de Unamuno carried out -both inspired by a passage of Dante - in their respective poems «Che fece...il gran rifiuto» (1901) and «La gran rehusa» (1910). These poems are analysed in the first place separately, stressing above all the repercussions they had on the literary critics. Finally, both poems are examined comparatively.
\end{abstract}

Keywords: Cavafis - Unamuno - Dante

Recibido: 20.12.18 - Aceptado: 31.05.19

Correspondencia: Styliani Voutsa

Email: svoutsa@yahoo.com

Universidad Aristótleles de Tesalónica, Doctora por la Universidad de Salamanca. Profesora de Educación Secundaria en Rodas, Grecia 


\section{1.- Constantinos Cavafis: «Che fece...il gran rifiuto»}

7 n 1901, el poeta griego Constantinos Cavafis (Alejandría, 1 1863-1933), escribe un poema inspirado en un pasaje de la Divina Commedia de Dante. El poema del alejandrino se titula «Che fece...il gran rifiuto»:

\section{CHE FECE ...IL GRAN RIFIUTO [1901]}

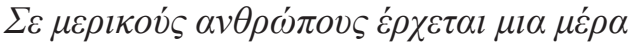

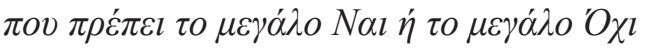

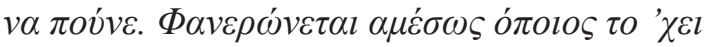

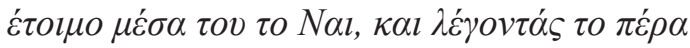

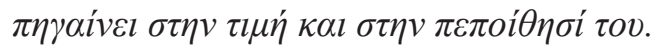

$O \alpha \rho v \eta \theta \varepsilon i \varsigma \delta \varepsilon v \mu \varepsilon \tau \alpha v o l \omega ́ v \varepsilon l . A v \rho \omega \tau o v ́ v \tau \alpha v \pi \alpha \dot{\lambda} \imath$,

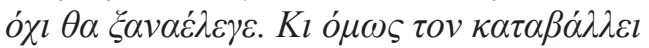

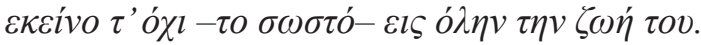

\section{CHE FECE ...IL GRAN RIFIUTO [1901]}

A ciertas personas llega un día en que deben decir el gran Sí o el gran No. Pronto aparece quien dentro lleva presto el Sí, y diciéndolo prosigue

adelante en su honor y propia convicción. Quien dijo No, no se arrepiente. Si de nuevo le preguntaran, diría No otra vez. Pero ese No - correcto para toda su vida lo avasalla.

(Traducción de Pedro Bádenas de la Peña) 


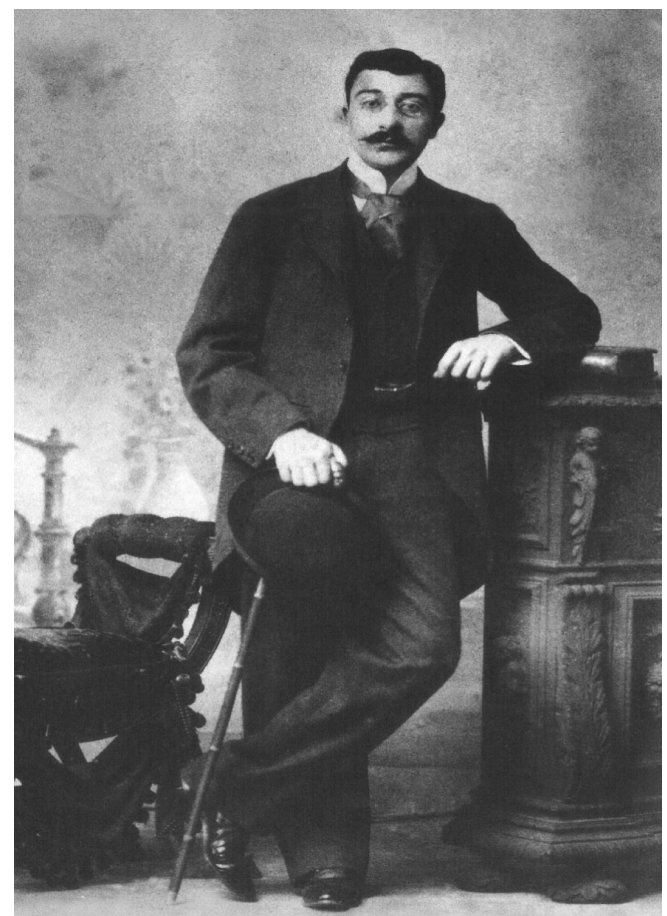

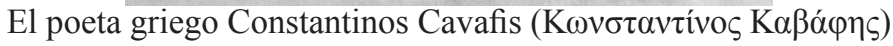

Se trata de uno de los poemas más conocidos y discutidos de C. Cavafis que pertenece, en cuanto a su temática, a los llamados poemas filosófico-didácticos, a menudo escritos en segunda persona («Ítaca», «El dios abandona a Antonio», "Satrapia», etc.), en los que el poeta expresa una actitud vital (vale la pena mencionar aquí que el traductor al castellano Pedro Bádenas de la Peña incluye «Che fece...il gran rifiuto» a la sección «Poemas del destino») ${ }^{1}$.

1 Según las notas del editor de Cavafis, del profesor Yorgos Savvidis, el poema se escribió en Junio de 1899 y se publicó por primera vez en la revista Panatenea

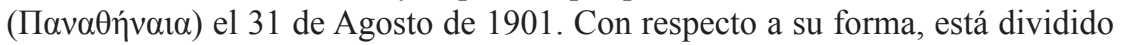
en dos estrofas simétricas (de cuatro versos cada una) con rima $a b b a, c d d c$. Por otra parte, vale la pena destacar también los encabalgamientos, sobre todo el que marca el cambio entre la primera y segunda estrofa («presto el Sí, y diciéndolo prosigue / adelante en su honor y propia convicción»). 
El título del poema es una adaptación de un verso del Canto III del Inferno de la Divina Commedia:

Poscia ch'io v'ebbi alcun riconosciuto, 57

vidi e conobbi l'ombra di colui

che fece per viltà il gran rifiuto.

Después que algunos hube conocido, reconocí a su sombra y paré mientes en quien la gran renuncia ha cometido.

(Traducción de Ángel Crespo)

El que «cometió la gran renuncia» no es otro que el papa Celestino $\mathrm{V}$ (Pietro di Murrone), que cinco meses después de haber sido elegido papa con ochenta años (1292), renunció voluntariamente a la tiara para volver a su vida de ermitaño en Calabria.

Giovanni Boccaccio (1313-1375), el autor del Decamerone y declarado admirador de Dante, en su texto «Esposizioni sopra la Comedia» relata detalladamente los acontecimientos que condujeron a la elección de Piero di Murrone (o Piero de Morrone) como papa Celestino V:

Vidi e conobbi l'ombra di colui / Che fece per viltà il gran rifiuto.

Chi costui si fosse con si sa assai certo; ma, per l'operazione la quale dice da lui fatta, estiman molti lui avere voluto dire di colui il quale noi oggi abbiamo per santo e chiamiamo san Piero del Morrone, il quale senza alcun dubbio fece un grandissimo rifiuto, rifiutando il papato. E dicesi lui a questo rifiuto essere in questa maniera pervenuto, che, essendo egli semplice uomo e di buona vita nelle montagne del Morrone in Abruzo sopra Sermona in atto eremitico, egli fu eletto papa in Perugia, appresso la morte di papa Niccola d' Ascoli; ed essendo il suo nome Piero, fu chiamato Cilestrino. ${ }^{2}$

2 BOCCACCIO, Giovanni. Tutte le opere. Tomo VI: Esposizioni sopra la Comedia di Dante. Edición de Vittore Branca. Verona: Arnoldo Mondadori, 1965, p. $148-149$. 
Boccaccio no se limita sólo a describir los hechos sino que narra también con mucha viveza y fuerza de introspección psicológica las maniobras y los entresijos que desembocaron en la renuncia de Celestino $\mathrm{V}$ :

La cui semplicità considerando, messer Benedetto Gatano cardinale, uomo avvedutissimo e di grande animo e disideroso del papato, astutamente operando, gli incominciò a mostrare che esso in pregiudicio dell' anima sua tenea tanto officio, poiché a ciò sofficiente non si sentia.

Alcuni vogliono dire che esso usò con alcuni suoi segreti servidori che la notte voci s' udivano nella camera del predetto papa, le quali, quasi d' angeli mandati da Dio fossero, dicevano: -Renuncia, Cilestrino! renuncia, Cilestrino! - Dalle quali mosso, ed essendo uomo idiota, ebbe consiglio col predetto messer Benedetto del modo del poter renunziare. Il quale gli disse: -Il modo sarà questo, che voi farete una decretale, nella quale si contenga che il papa possa nelle mani de' suoi cardinali renunziare il papato.

[...] E il dì di santa Lucia, essendo stato cinque mesi e alcun dì papa, venuto co' papali ornamenti in concistoro, in presenza de' suoi cardinali puose giù la corona el il papale ammanto e rifiutò il papato. Di che poi seguì, che la vilia di Natale messer Benedetto predetto fu eletto papa e chiamato Bonifazio ottavo. ${ }^{3}$

Como se puede apreciar, Boccaccio considera a Piero del Morrone una persona sencilla y benevolente hasta el extremo de la ingenuidad (llega a llamarlo ni más ni menos que «hombre idiota»), puesto que creyó enseguida lo que le contaba su contrincante, el astuto Benedetto.

Bien diferente es la postura que adopta Dante Alighieri. Según el autor de la Comedia, la actitud de Celestino V es la de un cobarde, puesto que rechaza la responsabilidad superior de regir la Iglesia. C. Peregrín Otero en su artículo «Unamuno y Cavafy: "Il gran rifiuto" insinúa que, en realidad, Dante censura a Celestino porque lo considera responsable de

3 Ibid., p. 149. 
sus desgracias personales y por su exilio. Otero argumenta que al abdicar Pietro di Murrone del papado y despojarse de la corona y del manto, dejó el camino libre para que subiera al trono papal Benedetto de' Caetani, llamado Bonifacio VIII. El nuevo papa, en colaboración con el monarca Carlos de Valois, empezó a favorecer a los 'neri' y a decretar el exilio de los güelfos blancos, entre los cuales se encontraba el poeta florentino, el «gran proscrito»y el «gran desdeñoso», según las palabras de Unamuno 4 :

Según el testimonio de Cacciaguida (Par. XVII, 49-54), es este «gran Prete» Bonifacio el responsable de planear, tramar y decretar el exilio e infortunio de Dante, lo que explica el rencor del airado vate y la dulzura de su imaginaria «vendetta» (Purg. XX, 94-6, y salmo LVIII, 10). Pero acaso el verdadero responsable no era Bonifacio, sino aquel que le había brindado la ocasión (Inf. XXVII, 103-5):

Lo ciel poss' io serrare e diserrare, como tu sai: però son due le chiavi, che 'o mio antecessor non ebbe care.

En esta cruel burla está la clave de la actitud del gran poeta cristiano. Si el antecesor de Bonifacio hubiera puesto más interés en las dos llaves (del cielo y de la tierra) que pueden abrirlo todo y cerrarlo todo, el destino personal del ilustre güelfo hubiera sido muy otro. Rehusa tan definitiva y extemporánea no se concibe sino por viltà, por muy humilde y santo que se sea. ${ }^{5}$

Por otra parte, la actitud de Cavafis en su poema «Che fece...il gran rifiuto» difiere mucho de la de Dante. A pesar de la condena expresa

4 Unamuno en su texto «Cómo se hace una novela» tiene numerosas alusiones a Dante y a su Divina Comedia, la cual compara con la 'Divina Tragedia' de la España de su tiempo. El pensador español, desterrado en Fuerteventura, siente su destino afín al de dos 'almas gemelas', otros dos 'grandes proscritos', Mazzini y Dante: «Mazzini era un desterrado, un desterrado de la eternidad. [Cómo lo fue antes de él el Dante, el gran proscrito -y el gran desdeñoso...]» (p. 103); «El otro gran proscrito, el más grande sin duda de todos los ciudadanos proscritos, el gibelino Dante, un soberano poeta, y un político y un creyente» (p. 121). (UNAMUNO, Miguel de. San Manuel Bueno Mártir. Como se hace una novela. Madrid: Alianza, 2000).

5 PEREGRIN OTERO, C. Unamuno y Cavafy: "Il gran rifiuto". Papeles de Son Armadans XXXVI, Madrid-Palma de Mallorca, 1965, pp. 271-272. 
del poeta italiano al papa Celestino, Cavafis no fustiga tal elección, sino que ve en el rechazo «una renuncia voluntaria, consciente y, hasta cierto punto,heroica, ante momentos de elección moralmente ineludible», según señala con tino su traductor y estudioso Pedro Bádenas de la Peña. En opinión del mismo crítico, el último verso del poema evoca las condenas de que fue objeto aquel papa dimisionario por parte de su sucesor Bonifacio VIII.

El poeta alejandrino, en su lectura personal del Inferno, introduce unos puntos suspensivos en el lugar del «per viltà» del original dantesco. Tal supresión indica que Cavafis considera elogiosa la actitud de Celestino: no abdicó por cobardía, sino todo lo contrario, por humildad. Como afirma otro traductor suyo, Ramón Irigoyen, el poeta alejandrino - a diferencia de Dante- «comprende plenamente la libertad total de la persona a la hora de elegir su destino» ${ }^{6}$. En efecto, Cavafis considera la actitud de aquel papa un acto voluntario y consciente, casi heroico y le da un valor ético universal. Lo mismo parece haber opinado la Iglesia oficial que en 1313, durante el papado de Clemente V, canonizó a Celestino V.

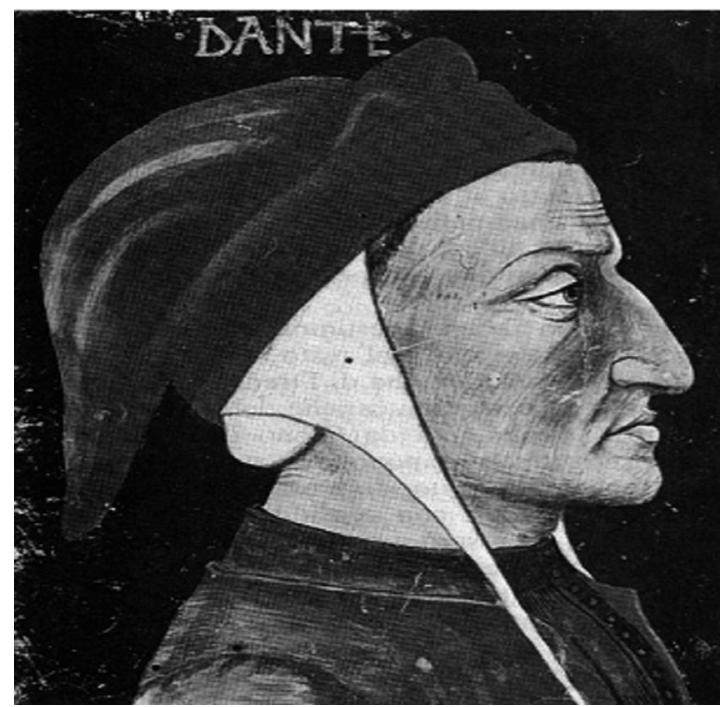

Retrato del poeta italiano Dante Alighieri. Firenze, Biblioteca Riccardiana.

6 C. P. CAVAFIS. Poemas. Traducción, prólogo y notas de Ramón Irigoyen. Barcelona: Seix Barral, 1994, p. 251. 
Según el neohelenista chileno y traductor de Cavafis, Miguel Castillo Didier, el poeta parte de «un hecho histórico motivador, para luego abandonarlo e independizar su propio pensamiento» ${ }^{7}$. Las afirmaciones del propio Cavafis sobre su poema en un texto suyo en inglés, parecen estar en consonancia con la opinión de su traductor:

Renunció, porque pensó consecuentemente, o que no es el adecuado para el cargo o que el cargo no le es merecido o que el cargo no debería realizarse o por otra causa lógica similar. Sin embargo, otro asumió el cargo y con éxito -posiblemente porque era el adecuado para ese cargo específico, o porque tenía a su disposición unos medios específicos, los cuales modificaron o facilitaron o mejoraron el cargo o sus resultados. El éxito de ese otro tiene una proyección negativa en el Renunciador, y ésta es la razón por la que, aunque el Renunciador supiera que su No era el correcto, no obstante, ese No le pesa en toda su vida -hacen que le pese las sospechas y las habladurías y las críticas y los malentendidos de los demás que son la mayoría. ${ }^{8}$

Como se puede apreciar del texto citado, parece que, para Cavafis, llega un momento en la vida que cada individuo tiene que tomar posición (coloquialmente, se diría 'tiene que mojarse'): seguir siendo uno él mismo o doblegarse a la multitud y seguirle la corriente. El precio que hay que pagar en el primer caso es muy caro: cuesta mucho ignorar la opinión de los demás que tiende a despistarnos y desorientarnos. En otras palabras, cuesta mucho ser uno mismo y no hacer caso a lo que pide y dicta la multitud que tiende a uniformarnos.

Ésta es nuestra interpretación personal de la lectura del poema y de las afirmaciones de Cavafis. Sin embargo, el poema sigue siendo extremadamente ambiguo (la sugestión siempre ha sido un rasgo

7 CASTILLO DIDIER, Miguel. Poetas griegos del siglo XX. Caracas: Monte Ávila editores, 1981, p. 162.

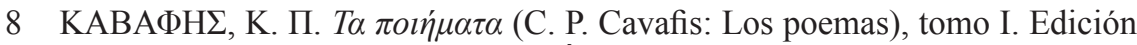
a cargo de Yorgos Savvidis. Atenas: Íkaros, 1997 [1963], p. 172. Traducción Styliani Voutsa. 
fundamental de la poesía cavafiana). De hecho, su temática no ha dejado de dar lugar hasta ahora a interpretaciones variopintas o, incluso, opuestas, siendo una verdadera 'opera aperta' (para recordar la terminología de Umberto Eco). En cuanto a su forma, vale la pena mencionar lo que se dice siempre sobre la poesía de Cavafis: a pesar de su expresión aparentemente 'fría' y 'neutra', casi 'antipoética' (entendido 'poética' en el sentido tradicional de la palabra), a pesar de su dicción narrativa y prosaica, el poema de Cavafis consigue transmitirnos emoción y conmovernos. ${ }^{9}$

A continuación, trataremos algunas opiniones e interpretaciones de la crítica cavafiana con respecto al poema «Che fece... il gran rifiuto»:

I) El poeta y premio Nóbel griego Yorgos Seferis, en su famoso artículo sobre Cavafis y Eliot («C. P. Cavafis, T. S. Eliot: paralelos»), señala que la multitud que pulula por los versos de La tierra baldía eliotiana son las personas que «por cobardía han cometido la gran renuncia» - che fece per viltà il gran rifiuto-, según señaló Dante en su Comedia. Para Seferis, los personajes que pueblan los versos de The waste land son seres humanos que en realidad no vivieron nunca, que renunciaron tanto el bien como el mal. Seres a los que ni siquiera el infierno puede aceptar, hombres que no han podido atravesar las aguas del río Aqueronte ${ }^{10}$ : muertos e ignorados por los siglos de los siglos. ${ }^{11}$

9 Ésta precisamente fue la pregunta principal de toda la crítica cavafiana hasta ahora: ¿Cómo es posible que alguien escriba poesía con medios expresivos de la prosa? ¿Cómo una poesía puede transmitir emoción, cuando su lenguaje no es emotivo, es decir, no es poético? Parece que el alejandrino guardaba bien los secretos de su taller estético.

10 Hijo de Helio y de Gea, transformado por Zeus en un río subterráneo como castigo por haber proporcionado agua a los titanes, que se habían revelado contra

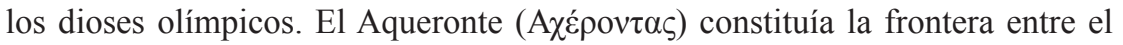
mundo de los vivos y el mundo de los muertos (los Infiernos). Las «sombras» de los muertos se acercaban a su orilla y eran recogidos allí por el barquero Caronte que los pasaba al otro lado. Era un viaje sin retorno (excepto en la doctrina mística de la reencarnación, de la que Virgilio se hace eco en el canto VI de la Eneida). [MARTÍN, René (dir.). Diccionario de Mitología Griega y Romana. Madrid: Espasa, Calpe, 1996].

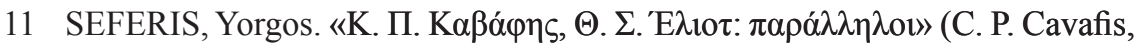

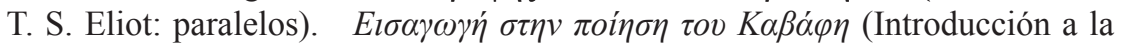
poesía de Cavafis), Heraklio, Ediciones de la Universidad de Creta, 2003 [1994], 
Sin embargo, en opinión de Seferis, el caso de Cavafis no se puede comparar a aquel de Eliot:

Pero en el reino del alejandrino no existe el "Caballero casto», el símbolo de la lucha entre el bien y el mal; el verso de Dante, que vimos cómo lo empleó Dante

Che fece il gran rifiuto

motivó a Cavafis para componer [...] quizá el más vulgarizado de sus poemas; su mayor fracaso, según mi modo de ver. Tal vez el único poema donde no mide bien sus palabras, y en el que contrapone, con alguna presunción y con mayúsculas, un «gran Sí» y un «gran No» incoherentes y sin razón de ser. Pero los problemas de los puritanos son rara vez problemas de los griegos, y Eliot habría sido quizás para Cavafis una especie de Juliano ${ }^{12}$, un Juliano puritano, el personaje más burlado de su obra. ${ }^{13}$

Es obvio que, para Seferis, en la idiosincrasia del pueblo griego no caben puritanismos y luchas entre el bien y el mal. Aparte de eso, según el poeta premio Nóbel, el Cavafis de «Che fece...il gran rifiuto» no es el Cavafis maduro, el poeta que conocemos y admiramos: todavía no había encontrado su voz personal e inconfundible, la de la insinuación y la sugestión.

II) Según Francisco Rivera, traductor venezolano de la poesía del alejandrino, "Cavafy suprime del verso las palabras "per viltà" ("por cobardía"), pues considera que -por más aplastante que sea para quien lo dice- el "gran No", "tan justo", requiere coraje» ${ }^{14}$. Rivera señala que

\section{p. 164.}

12 Se refiere al emperador Juliano el Apóstata (361-363 d. C.) a quien Cavafis le dedica 7 poemas.

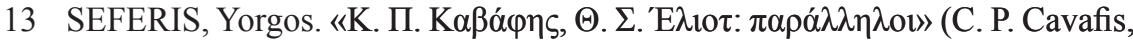

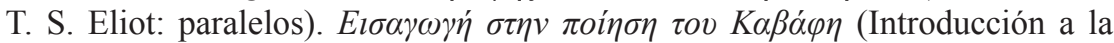
poesía de Cavafis), Heraklio, Ediciones de la Universidad de Creta, 2003 [1994], p. 166.

14 CAVAFY, C. P. Cien poemas. Traducción y prólogo de Francisco Rivera. 
se trata de uno de los más famosos poemas griegos, a pesar de la crítica negativa de Yorgos Seferis (crítica con la que él declara que se siente totalmente identificado) de ser una composición demasiado grandilocuente y de presentar una problemática puritana ajena a la mentalidad griega.

III) Yannis Sareyannis, uno de los más relevantes estudiosos de Cavafis y amigo personal del poeta (botánico de oficio), señala que la poesía del alejandrino avanza siempre con tesis y antítesis, en otras palabras, tiene un carácter marcadamente dramático. En el poema "Che fece...il gran rifiuto», Sareyannis analiza el binomio personas del Si / personas del No: el poeta establece una bipolaridad, nos habla de dos categorías de personas. Los límites de cada categoría están bien definidos: el que pertenece a la primera por mucho que quiera pasar a la otra, no podrá conseguirlo.

Según Sareyannis, el mundo de muchos héroes cavafianos se separa en dos: el Dentro (gr. $\mu \dot{\varepsilon} \sigma \alpha /$ mesa) y el Fuera (gr. $\dot{\varepsilon} \xi \omega /$ exo), el interior y el exterior, el microcosmos y el macrocosmos. ${ }^{15}$ La incompatibilidad de estos dos mundos crea de por sí contrastes dramáticos. Para el héroe cavafiano del No, el encerrarse en el mundo de 'dentro', en sus «Murallas», es una necesidad, una pasión tan intensa como las pasiones que vemos representadas en las tragedias griegas (por ejemplo la pasión erótica de Medea). En otras palabras, es la pasión del héroe cavafiano por el mundo interior. Porque el alma humana, como dice Sareyannis, tiene muchos más niveles de pasión que el que inspira el Eros. ${ }^{16}$

El héroe del No constantemente se autoanaliza, está todo el tiempo en desacuerdo trágico con su entorno, o, como afirma Minkowski en La schizophrenie, está dividido entre el «yo y el mundo». ${ }^{17}$ No obstante, las personas del sí, es decir, del 'fuera', son felices. No les importa para nada carecer de un mundo interior. Cavafis dramatiza muy bien en sus poemas este conflicto entre el dentro y el fuera.

Caracas: Monte Ávila editores, 1978, p. 148.

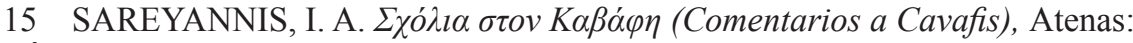
Íkaros, 1973 [1964], pp. 52-53.

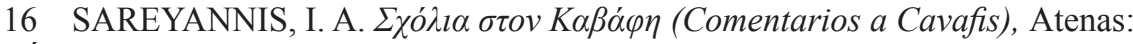
Íkaros, 1973 [1964], p. 62.

17 Ibid., p. 60. 
Finalmente, para Sareyannis, existe una tercera categoría de hombre: es el que no llega a decir que Sí pero tampoco se decide por el No: «El poeta entre las personas del Sí y del No, destaca un nuevo tipo de hombre, que no llega hasta la decisión de decir 'sí', pero tampoco llega a la negación del 'no'» ${ }^{18}$. Se trata del protagonista cínico de los poemas «Que se hubieran preocupado» y «De la escuela del famoso filósofo». Este tercer hombre tiene también rasgos dramáticos, como los dos anteriores. «Su drama es la libertad, la absoluta libertad». ${ }^{19}$ Con esta última afirmación de Sareyannis, estamos muy cerca de los postulados existencialistas y las enseñanzas de Sartre.

IV) José María Álvarez traduce la poesía completa de Cavafis al castellano en 1976 (ed. Hiperión). En las notas que tiene sobre el poema «Che fece...il gran rifiuto», Álvarez hace eco de la opinión de Stratís Tsirkas, novelista y crítica griego y uno de los más importantes estudiosos de Cavafis.

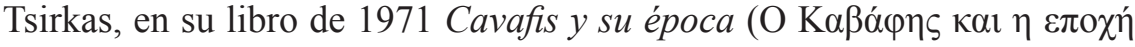

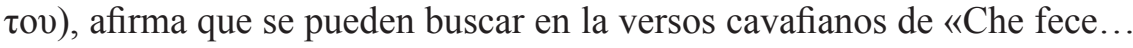
il gran rifiuto» referencias que remiten a acontecimientos contemporáneos de Cavafis. En concreto, Tsirkas defiende que la renuncia de Celestino V al papado alude a la renuncia del patriarca ecuménico Joaquín III a la sede episcopal de Alejandría en 1884. Tsirkas ve también en la raíz del mismo poema otras claves personales del poeta (por ejemplo, su renuncia de adquirir la nacionalidad británica en 1885). Sin embargo, tales propuestas no resultan muy plausibles. Robert Liddell, el autor de la Biografía Crítica de Cavafis, rechaza la interpretación de Tsirkas reproducida por Álvarez: el argumento de Liddell es que Joaquín III aceptó ser reelegido en el trono de Constantinopla en 1901 y ocupó esta sede hasta su muerte, de modo que el caso de Celestino V que cuenta Cavafis no se puede prestar a tales paralelismos $^{20}$. Por nuestra parte, queríamos recordar que S. Tsirkas en los dos célebres libros que tiene sobre el poeta alejandrino (Cavafis político [O

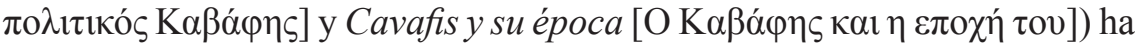
defendido a menudo interpretaciones sociopolíticas de la obra cavafiana.

18 Ibid., p. 72.

19 Ibid., p. 72.

20 LIDDELL, Robert. Kavafis. Una Biografia. Traducción de Carles Miralles. Barcelona: Paidós, 2004, p. 101. 
V) El poeta español Jaime Gil de Biedma (1929-1990) dedica un ensayo de su libro El pie de la letra a Juan Gil Albert, en el que compara la figura del poeta alicantino con el viejo poeta alejandrino y encuentra un correlato de la actitud vital de Gil Albert en la actitud del protagonista cavafiano del poema "Que fece...il gran rifiuto». El pasaje es interesantísimo, y demuestra que Gil de Biedma conocía datos de la biografía y de la situación familiar de Cavafis y, además, tenía en cuenta el famoso texto que escribió sobre él E. M. Forster ${ }^{21}$, en el que el novelista inglés describe a Cavafis como «un gentleman griego, tocado con un sombrero de paja, en pie y absolutamente inmóvil, en una posición oblicua en relación al universo». Por su especial interés, consideramos oportuno citar el pasaje de Jaime Gil entero:

A veces, paseando en Valencia con Juan Gil Albert, al detenerse y tomarme del brazo [...] vuelto el rostro hacia mí en toda su expresión ponderativa, inquisitiva y cauta, entre el ruidoso agobio de los transeúntes, me he acordado de otro oscuro y envejecido señor, también menudo e inmaculadamente vestido, de otra ciudad que apenas, tampoco, puede ser considerada una metrópoli del espíritu, y que fue uno de los seres menos provincianos que han existido en el mundo. Un caballero griego de hace sesenta años, inmóvil en una calle de Alejandría, en una posición ligeramente oblicua respecto al universo, mientras comenta el precio de las aceitunas o las pérfidas maniobras del emperador Alejo Comneno en 1096...Constantinos Cavafis, según se muestra en el afectuoso retrato de E. M. Forster.

Tal superposición de imágenes no responde, por cierto, a una apreciación de orden estético, no implica paridad de valor entre la obra de uno y la del otro, ni semejanza. Juan Gil Albert no es «el Cavafis español», para emplear un

21 Fragmento del ensayo - considerado hoy clásico- que publicó el novelista E. M. Forster en 1919 en la revista Athenaeum de Londres, y reproducido luego en el libro Pharos y Pharillon, en 1923. Forster realizó también traducciones de poemas cavafianos y dió a conocer la obra del alejandrino a otros escritores, como D. H. Lawrence, Arnold Toynbee y T. S. Eliot. 
estereotipo de nuestro inveterado provincianismo cultural. La afinidad entre el britanizado griego de Alejandría y el afrancesado valenciano de Alcoy es de otra índole, y es honda. No se restringe a los pequeños detalles anecdóticos recogidos en mi evocación y a otras muchas coincidencias en gustos, actitud, temperamento y circunstancias -la ruina económica, por ejemplo, que juega un papel decisivo en las vidas de ambos-, y a la carencia de provincianismo, la indeclinable adscripción al propio medio familiar y social y la mediterraneidad -estrictamente urbana y ribereña en Cavafis, entreverada de pueblerina ruralía en Gil Albert-. La afinidad última, y asimismo el contraste, reside en el hecho de haber sido también Cavafis un exiliado en su tierra. $^{22}$

Gil de Biedma cita en el mismo ensayo el poema «Che fece...il gran rifiuto». Su lectura personal del poema y la extrapolación que hace en el contexto que le interesa es -a nuestro parecer- extraordinaria:

Aunque la mayoría de los poemas del griego fueron escritos después de los cuarenta y ocho años, a una edad en que el sentido de su vida aparece tan claro y tan perfecto como un libro, entre el puñado de composiciones anteriores a 1911, una, Che fece... il gran rifiuto, permite inferir que su autor conocía muy bien el precio que a veces ha de pagarse para llegar a ser uno mismo. Significativamente, podríamos atribuirla a Gil-Albert - un homenaje al papa Celestino V, por supuesto-:

Hay hombres en la vida, a quienes llega el día de pronunciar el Sí o el No definitivos.

Quien al Sí estaba presto, con su Sí se revela y prospera en la estima de los otros según su propia estima, satisfecho de sí mismo.

Aquel que rehusó tampoco se arrepiente:

22 GIL DE BIEDMA, Jaime. El pie de la letra. Ensayos completos. Barcelona: Crítica (Grijalbo Mondadori), 1994 [1980], pp. 309-310. 
de nuevo preguntado, diría otra vez No.

Aunque ese justo No le abruma para siempre.

Jaime Gil compara la postura ética que refleja Cavafis en este poema con la de otro poeta mediterráneo, de Juan Gil Albert:

Está claro que Cavafis, por encima del Sí, valora el No, mediante el cual sólo se prospera en la aceptación de uno mismo; pues quien ha dicho No, defraudando las expectaciones y renunciando a la estima de sus conciudadanos, automáticamente se convierte en un exiliado en su tierra. Imposible saber si esos versos responden a una particular experiencia del poeta y, de ser así, en qué consistió. En cualquier caso, y por dolorosa que resulte, la certeza que expresan es total: antes que el hombre, y en su lugar, ya estaba el No. Pronunciarlo es reconocerse lúcidamente, el que se es. Porque para Cavafis, vástago de una familia originaria de Constantinopla, hijo de Alejandría, griego de la diáspora, antes que cierto destino individual, el exilio en su tierra fue condición de nacimiento, mejor dicho, de nación. A ella se acoge. Enlazando, por encima de los siglos, con el cosmopolita mundo helenístico de los Diadocos o con Bizancio, tranquilamente la asume como un distintivo de estirpe, fundamento de su singularidad. Encastillado en ella, seguro de quién es, apenas necesita publicar sus versos: unas pocas hojillas impresas, parsimoniosamente distribuidas, le bastarán mientras espera el día en que la muerte selle su destino. Hay quid pro quo gloriosos. ${ }^{23}$

Para Jaime Gil, el destino que une a Constantinos Cavafis y a Juan Gil Albert es el sentirse exiliados en su propia tierra. Y este exilio puede aludir tanto a asuntos políticos como a su propia condición de homosexuales. En este grupo cabría incluir también a otro gran exiliado, un «español a pesar suyo» (como lo llama Biedma), que siempre sintió España como una madrastra y a sus paisanos como un pueblo atrasado que se ofendía por sus escritos: el sevillano Luis Cernuda. Y quizás, cabría incluir al

23 El pie de la letra, pp. 310-311. 
propio Gil de Biedma que, a nuestro juicio, también tenía preparado el No desde siempre. Habiendo discutido con su pasado y la clase burguesa que representaba, Jaime Gil pagó el precio de ser él mismo. Así se sintió toda la vida un exiliado, ajeno a la clase que lo crió y le dio una infancia feliz («burguesito en rebeldía», se autocaracterizó en su Diario). Esta escisión, junto con su condición de homosexual (u «homosentimental» como decía é $\left.{ }^{24}\right)$ lo acompañó como cadena perpetua para toda la vida.

\section{2.- Miguel de Unamuno: «La gran rehusa»}

Nueve años más tarde que Cavafis, en 1910, el gran autor y pensador español Miguel de Unamuno (Bilbao,1864 -Salamanca,1936) escribe un soneto titulado «La gran rehusa», basado en el mismo pasaje de Dante pero sin la más leve relación con el poema de Cavafis:

\section{XXVIII}

\section{LA GRAN REHUSA}

Vidi e conobbi l' ombra di colui che fece per viltate il gran rifiuto.

(DANTE; Inferno, III, 59-60.)

AL abrigo fatal de la cogulla con que te encubres el altivo ceño se incuba libre el ambicioso ensueño que soledad con su silencio arrulla.

Del mundo huyendo la inocente bulla, vuela adusto tu espíritu aguileño en torno, no del sacrosanto leño que con su yugo al corazón magulla, sino del solio. Aunque la plaza huiste la plaza llevas dentro y es la musa

24 «Antes que homosexual soy rabiosamente homosentimental» (GIL DE BIEDMA, Jaime: Retrato del artista en 1956, p. 71). 
con que Satán te pone el alma triste,

la que te dio la vocación confusa por la que adiós a tu familia diste, que no, cobarde, harás la gran rehusa.

Salamanca, 22 de Septiembre, $1910 .^{25}$

El poema pertenece al libro Rosario de sonetos líricos (1911) $\mathrm{y}$, en particular, a la sección «En casa ya». ${ }^{26} \mathrm{Al}$ parecer, en el epígrafe que encabeza su poema, Unamuno no suprime - como hizo Cavafis- las palabras del original dantesco «per viltà». Sin embargo, al final de su poema el poeta español, igual que el alejandrino, deja cierta ambigüedad. Esta oscuridad semántica culmina en el último verso: «que no, cobarde, harás la gran rehusa». ¿Es la actitud del protagonista cobarde o no? En nuestra opinión, la pregunta no queda contestada. La coma que se interpone en medio del verso, enmarcando la palabra 'cobarde', dificulta la interpretación, recordándonos aquellos vaticinios de los oráculos griegos antiguos que según la colocación de los signos de puntuación cambiaba el sentido de la frase entera.

A continuación, citaremos las opiniones de tres estudiosos españoles sobre el poema de Unamuno:

I) Carlos Peregrín Otero en su artículo citado «Unamuno y Cavafy: “il gran rifiuto"» (1965) establece una comparación entre el poema cavafiano y el soneto de Unamuno. Otero comienza su artículo enumerando las coincidencias y caminos paralelos de -lo que él llama- «vidas sincrónicas» de Cavafis y de Unamuno. Señala, por ejemplo, que Cavafis empieza a publicar con 41 años (en 1904) y Unamuno con 42 (en 1907); o que Cavafis se retira de su empleo de funcionario en 1922, mientras que Unamuno es separado de su cátedra y exiliado a Fuerteventura en 1924; o, finalmente, cuando afirma que desde 1925 hasta 1930 Unamuno vive entre sus vascos

25 UNAMUNO, Miguel de. Obras Completas VI: Poesía. Edición de Manuel García Blanco. Madrid: Escelicer, 1966.

26 El libro se divide en varias partes, ateniéndose a los lugares en que fueron compuestos los sonetos. Todos los poemas de «En casa ya» están escritos en Salamanca. 
en Hendaya, igual que Cavafis entre sus griegos en Alejandría. Y la lista de fechas y simultaneidades sigue así...

Para Peregrín Otero, «a la simultaneidad temporal de sus vidas corresponde una como polaridad espacial de sus mundos»: Cavafis nace en «la soleada Alejandría» mientras que Unamuno en «el brumoso Bilbao»; Cavafis tiene un «alma pagana», mientras que Unamuno se siente con un «alma medieval» ${ }^{27}$. Sin embargo, la confusión que manifiesta Peregrín Otero es cuando sostiene que al poeta alejandrino no le caracterizaba el ansia de fama e inmortalidad que poseía el poeta vasco y que lo único que preocupaba a Cavafis era lo terrenal, lo histórico, lo de todos los días. ¡Qué equivocación! Primero: es archiconocido que Cavafis sí que se preocupaba por su fama póstuma y la suerte que iba a tener su obra tras su muerte (véase el poema «Muy raramente»). Segundo: a Unamuno le importaba lo trascendental y la inmortalidad, pero siempre vistos tales conceptos en su relación estrecha con lo terrenal y lo humano, con «el hombre de carne y hueso», como él solía decir.

Con respecto al poema de Cavafis, Peregrín Otero parece estar de acuerdo con la afirmación de Yorgos Seferis, de que no es uno de los momentos más felices de la producción cavafiana y, por tanto, no cabe considerarlo como representativo del poeta: «Falta todavía la visión personal, la dramatización concreta y diferenciada, el destaco objetivador, la ironía insinuante, el concentrado chispazo expresivo», señala con tino Otero. $^{28}$

En cuanto al poema de Unamuno, el autor del artículo indica que hay que buscar su paralelo en el ensayo filosófico Del sentimiento trágico de la vida, obra que considera «gemela» de «La gran rehusa». Sobre todo, hay que relacionar este soneto con el tercer capítulo de Del sentimiento trágico de la vida que se titula «El hambre de inmortalidad». Allí Unamuno cita a Dante y, en concreto, los versos que encabezan el canto III del Infierno: «Lasciate ogni speranza»:

27 PEREGRÍN OTERO, C. Unamuno y Cavafy: “il gran rifiuto". Papeles de Son Armadans XXXVI, Madrid-Palma de Mallorca, 1965, p. 260.

28 PEREGRÍN OTERO, C. Unamuno y Cavafy: “il gran rifiuto". Papeles de Son Armadans XXXVI, Madrid-Palma de Mallorca, 1965, p. 276. 
Y he de confesar, en efecto, por dolorosa que la confesión sea, que nunca, en los días de la fe ingenua de mi mocedad, me hicieron temblar las descripciones, por truculentas que fuesen, de las torturas del infierno, y sentí siempre ser la nada mucho más aterradora que él. El que sufre vive, y el que vive sufriendo ama y espera, aunque a la puerta de su mansión le pongan el «iDejad toda esperanza!», y es mejor vivir en dolor que no dejar de ser en paz. ${ }^{29}$

La conclusión a la que llega P. Otero en su artículo es que el poeta vasco en «La gran rehusa» (o mejor dicho en «El gran Rehusador») refleja el ansia de inmortalidady de ser de veras que tanto le preocupó siempre y, sobre todo, en la época en que escribe el Rosario. ${ }^{30}$

Con respecto a su forma, «La gran rehusa» es una composición con unidad argumental (ascendente en la octava, descendente hacia la conclusión en el sexteto) que desemboca en el verso enigmático final y su «engañosa coma»: «que no, cobarde, harás la gran rehusa». P. Otero sugiere que el gran rehusador del soneto parece tener no poco de «mojigato»y «gazmoño».

29 UNAMUNO, Miguel de. Del sentimiento trágico de la vida. Madrid: Alianza, 1997, p. 62. Unamuno vuelve a citar el dantesco «Lascate ogni speranza» en el décimo capítulo de su libro Del sentimiento trágico de la vida que lleva por título «Religión, mitología de ultratumba y apocatastasis»:

Y el alma, mi alma al menos, anhela otra cosa; no absorción, no quietud, no paz, no apagamiento, sino eterno acercarse sin llegar nunca, inacabable anhelo, eterna esperanza que eternamente se renueva sin acabarse del todo nunca. [...] Un dolor, una pena, gracias a la cual se crece sin cesar en conciencia y en anhelo. ¡No pongáis a la puerta de la Gloria como a la del Infierno puso Dante el Lasciate ogni speranza! ¡No matéis el tiempo! Es nuestra vida una esperanza que se está convirtiendo sin cesar en recuerdo que engendra a su vez a la esperanza. ¡Dejadnos vivir! La eternidad, como un eterno presente, sin recuerdo y sin esperanza, es la muerte. Así son las ideas; pero así no viven los hombres (Del sentimiento trágico de la vida, p. 263).

30 Con su exageración de siempre, P. Otero apunta: «Unamuno ve en Dante el alma medieval de Unamuno, el ansia de gloria (soneto XXVI) de Unamuno, las pasiones políticas de Unamuno, el fanatismo de Unamuno, el malhumorismo de Unamuno» (PEREGRIN OTERO, C.: «Unamuno y Cavafy: "il gran rifiuto" », p. 292). 
El artículo de P. Otero tuvo recepción variada por parte de los traductores de Cavafis al castellano. Mencionemos dos ejemplos: el filólogo neohelenista Pedro Bádenas de la Peña encuentra el artículo muy interesante en lo que trata la personalidad de ambos autores (Unamuno y Cavafis), mientras que otro filólogo neohelenista, Ramón Irigoyen, en las notas al «Che fece...il gran rifiuto» se muestra muy crítico con el artículo de Otero.

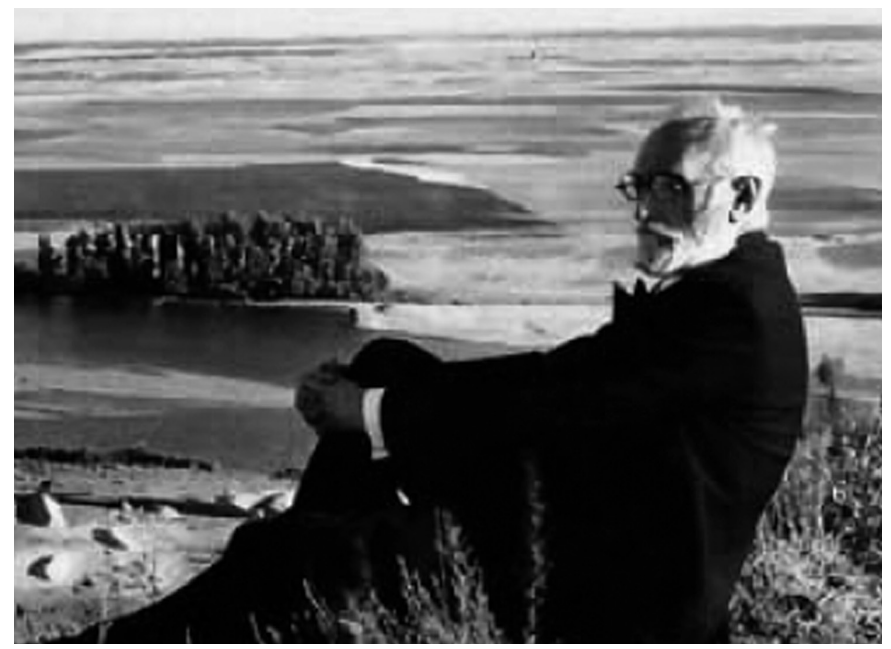

El filósofo, catedrático y escritor español Miguel de Unamuno

II) Vicente González Martín, catedrático de Filología Italiana de la Universidad de Salamanca y eminente estudioso de Unamuno, en su libro La cultura italiana en Miguel de Unamuno (1978) tiene sus objeciones a la afirmación de P. Otero de que el pensador vasco «nunca pretendió desautorizar la desdeñosa condena de Dante». El italianista español señala que tal juicio es cierto solamente en parte, puesto que en sus artículos «Políticos y literatos» (1904) y «Monje seglar» (1925) Unamuno justifica la rehusa y no la considera una cobardía sino «un deseo de alcanzar más alta gloria futura, huyendo de la inmediata ${ }^{31}$.

González Martín a partir del texto unamuniano «Monje seglar», da su propia interpretación del soneto unamuniano:

31 GONZÁLEZ MARTÍN, Vicente. La cultura italiana en Miguel de Unamuno. Salamanca: ed. Universidad de Salamanca, 1978, p. 110. 
Creo que Unamuno, aceptando en el soneto lo que de desdeñosidad y positivo hay en el ataque a los neutros, en el pasaje de Dante, lleva su interpretación más lejos, viendo en el rechazo de Celestino $\mathrm{V}$ un ansia profunda de inmortalidad por parte de éste. ${ }^{32}$

El autor de La cultura italiana en Miguel de Unamuno concluye que el 'gran rehusador' puede identificarse con Jesucristo, de modo que, resultan muy elocuentes por eso las expresiones «sacrosanto leño» y «Satán»:

Pienso que algunas expresiones del soneto: «sacrosanto leño» y «Satán» pueden dar a entender que en el poema el rehusador es en parte Jesucristo, pues en 'Monje seglar' nos habla de que Este no aceptó ser proclamado rey por las turbas. $^{33}$

III) El célebre italianista español, Joaquín Arce, en su libro Literaturas Italiana y Española frente a frente y, en concreto, en el capítulo que dedica al siglo XX, comenta dos poemas de Unamuno inspirados en Dante. El primero es el que hemos citado, «La gran rehusa», que Arce caracteriza como«soneto enigmático». Según él, no hay nada en este poema que recuerde al personaje de Celestino $\mathrm{V}$, excepto el sintagma final «la gran rehusa». Sin embargo, ésta gran rehusa no se hace por cobardía (que es la causa que le atribuye Dante) sino por desdén a la vida mundana:

Mi opinión es que Unamuno representa en su soneto a Celestino V antes del rechazo de la dignidad papal, cuando, vestido todavía con su hábito de eremita, había vencido su tentación de vivir en la bulla del mundo; el hacerse papa era precisamente alimentar esa satánica «vocación confusa» de gloria, por lo que Unamuno le predice que hará la gran renuncia, pero no por un acto de cobardía (viltà), que es la causa de que Dante lo condene, sino por vencer una vez

32 Ibid., p. 110.

33 Ibid., p. 110. 
más su ansia de vida mundana. ${ }^{34}$

El segundo poema que comenta J. Arce pertenece a las Rimas de dentro: se trata de una composición bellísima que lleva también como epígrafe un verso del Infierno dantesco (V, 127-128): Noi leggevamo un giorno per diletto / di Lancilotto L $^{35}$. Según Arce, igual que en el caso de «La gran rehusa», Unamuno toma una secuencia del original dantesco que trata una determinada situación y ambiente y realiza su lectura personal de esa situación y de ese ambiente. De manera que, el texto italiano le sirve a Unamuno de «punto de partida para una creación lírica con desarrollo autónomo» ${ }^{36}$ Lo mismo opinó, como vimos, el estudioso chileno, Miguel

34 ARCE, Joaquín. Dos muestras clave del siglo XX. Literaturas Italiana y Española frente a frente. Madrid: Espasa-Calpe, 1982, p. 339.

35 Rima XI

Noi leggevamo un giorno per diletto di Lancilotto

Fue así, leyendo un libro -isempiternos galeotos! -, fue así; luego subieron de las páginas

los ojos a los ojos,

y las manos que juntas lo tenían

se soltaron de pronto...

Soltáronse para subirse al cuello, para crisparse en gozo;

soltáronse para un más recio nudo de pechos anhelosos...

Y el libro se cerró a su propio peso, testigo mudo y sordo...

¿Sordo? ¡Quién sabe!...¡Quién sabe si mudo!

Ese libro hablará; ¡lo dirá todo!

¡Qué de historias no celan en sus páginas

los libros, los galeotos!

¡Y no se callan, no; temprano o tarde

revelan, fieles, sus secretos todos!

7-8 de mayo, 1909.

36 ARCE, Joaquín. Dos muestras clave del siglo XX, Literaturas Italiana y Española frente a frente. p. 340. 
Castillo Didier, sobre el poema cavafiano «Che fece...il gran rifiuto». Con este comentario nos identificamos también nosotros: es decir, ambos poetas, Cavafis y Unamuno, parten de un pasaje dantesco, y a propósito de él, hacen su lectura personal de la situación y de los personajes.

Según Vicente González Martín, el poema «Noi leggevamo un giorno per diletto/ di Lancilotto», será un preludio del gran influjo dantesco en la poesía de Unamuno. ${ }^{37}$

\section{3.- «Che fece...il gran rifiuto» $\mathbf{y}$ «La gran rehusa» vistos de manera comparada}

El poema de Constantinos Cavafis y el de Miguel de Unamuno se escriben en fechas muy cercanas: en 1901 el primero, en 1910 el segundo. Sin embargo, no existe la mínima relación entre las dos composiciones; más aún, son muchas las diferencias entre ellas. Se podría afirmar que lo único que tienen en común es el pasaje dantesco que les inspira.

El caso de los dos poemas, «Che fece... il gran rifiuto» y el soneto «La gran rehusa» pertenecería a lo que se ha venido llamando en la Literatura Comparada «el polen de ideas». Se trata de un concepto introducido por William Faulkner, cuando éste último cansado ya de que le preguntaran sobre la influencia que había ejercido en él James Joyce, contestó a un periodista que no todo se explica necesariamente por influencias y que las ideas flotan en el aire y pueden fertilizar del mismo modo mentes aquí y allá. Por consiguiente, se puede dar que autores que nunca han tenido un contacto directo, produzcan obras similares en formas, temas, y motivos: "You know, sometimes I think there must be a sort of pollen of ideas floating in the air, which fertilizes similarly minds here and there which have not had direct contact», señaló con tino Faulkner ${ }^{38}$.

El comparatista español Darío Villanueva en su libro El Polen de Ideas (1991), define tal concepto como «coincidencias poligenéticas de formas, temas e innovaciones más allá de un ámbito literario o cultural reducido», ${ }^{39} \mathrm{y}$ explica que esta imagen le viene asociada al pensamiento

37 GONZÁLEZ MARTÍN, Vicente. La cultura italiana en Miguel de Unamuno, p. 111.

38 Palabras de Faulkner que aparecen como lema en el libro El polen de ideas de Darío Villanueva (Barcelona, Proociones y Publicaciones Universitarias, 1991).

VILLANUEVA, Darío. El polen de ideas, p. 10. 
crítico de T. S. Eliot:

Como es bien sabido, para el poeta de The Waste Land todos los escritores, desde Homero hasta el propio Joyce, son contemporáneos entre sí, y también lo son nuestros, de forma que ninguna literatura está completa en sí misma, ni se puede comprender una obra cualquiera sin el apoyo de otras lecturas, cuanto más numerosas mejor . ${ }^{40}$

De modo que para la Literatura Comparada de hoy, basada en conceptos como analogías y paralelismos ${ }^{41}$, y habiendo dejado atrás por desfasados conceptos como rapports de fait, imitaciones e influencias, poco interesa si las composiciones aquí analizadas del poeta griego y del poeta español respectivamente hayan tenido una relación de causa o efecto, es decir, una relación genética. Lo que importa es la lectura personal ética y estética que hizo cada poeta del original dantesco y su transformación en una obra completamente nueva. En otras palabras, lo que importa es la Literatura como «yuxtaposición intensiva de dos o más composiciones no necesariamente relacionadas por causa ${ }^{42}$, en definitiva, la literatura sin fronteras temporales y geográficas y vista siempre a través de la mirada comparatista, sin la cual, como advierte D. Villanueva, ningún hecho referente a ella puede explicarse de forma cabal. ${ }^{43}$

\section{Bibliografía citada y consultada}

ALIGHIERI, D. (1973) Divina Commedia. Inferno. Edición bilingüe italianoespañol. Traducción, prólogo y notas de Ángel Crespo. Seix Barral: Barcelona.

ARCE, J. (1982). «Dos muestras clave del siglo XX», en Literaturas Italiana y Española frente a frente. Espasa -Calpe: Madrid.

BOCCACCIO, G. (1965). Tutte le opere. Tomo VI: Esposizioni sopra la Comedia di Dante. Edición de Vittore Brana. Arnoldo Mondadori: Verona.

40 Ibid., p. 9.

41 MARINO, Adrian. Comparatisme et théorie de la littérature. Paris: Presses Universitaires de France, 1988.

42 REMAK, Henry. El futuro de la literatura comparada. Orientaciones en Literatura Comparada. Madrid: ssArco Libros, 1998.

43 VILlANUEVA, Darío: Prólogo a CARTELle MONTERO, Enrique y HERRERO INGELMO, María de la Cruz. De Virgilio a Umberto Eco. Madrid: Ediciones del Orto-Universidad de Huelva, 1994. 
CASTILlO DIDIER, M. (1981). Poetas griegos del siglo XX. Monte Ávila editores: Caracas.

CAVAFIS, C. P. (1982). Poesía completa. Traducción, introducción y notas de Pedro Bádenas de la Peña. Alianza: Madrid.

--- (1973). 70 poemas. Traducción, prólogo y notas de Lázaro Santana. Visor: Madrid.

--- (1994). Poemas. Traducción y prólogo de Ramón Irigoyen. Seix Barral: Barcelona.

--- (1956). Poesie scelte. Versioni di Filippo Maria Pontani con un «ricordo» di Giuseppe Ungaretti. All' insegna del pesce d’ oro: Milán.

--- Collected poems (ed. revisada). Traducción de Edmund Keeley y Philip Sherrard. Princeton University Studio Press: Princeton, New Jersey.

--- (1978). Cien poemas. Traducción y prólogo de Francisco Rivera. Monte Ávila editores: Caracas.

--- (1962). The complete poems. Traducción de Rae Dalven e introducción de W. H. Auden. Harcourt: New York.

GIL DE BIEDMA, J. (1980). El pie de la letra. Ensayos completos. Crítica (Grijalbo Mondadori): Barcelona.

--- (1991). Retrato del artista en 1956. Lumen: Barcelona.

GONZÁLEZ MARTÍN, V. (1978). La cultura italiana en Miguel de Unamuno. ediciones de la Universidad de Salamanca: Salamanca.

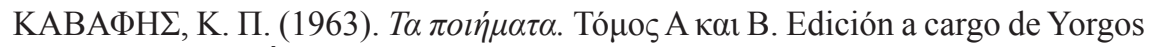
Savvidis. Íkaros: Atenas.

LIDDELL, R. (2004). Kavafis. Una Biografia. Traducción de Carles Miralles. Paidós: Barcelona.

MARTÍN, R. (dir.) (1996). Diccionario de Mitología Griega y Romana. Espasa Calpe: Madrid.

PEREGRÍN OTERO, C. (1965). «Unamuno y Cavafy: "il gran rifiuto”». Papeles de Son Armadans XXXVI, Madrid-Palma de Mallorca, pp. 253 -294.



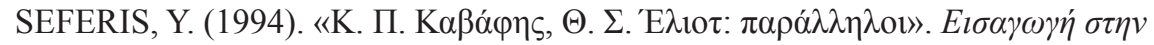

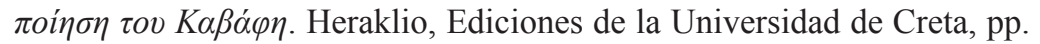
141-177.

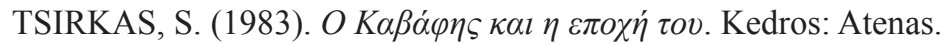

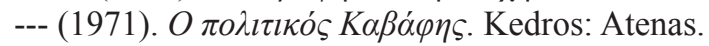

UNAMUNO, M. (2000). San Manuel Bueno Mártir. Como se hace una novela. Alianza: Madrid.

--- (1997). Del sentimiento trágico de la vida. Alianza: Madrid.

--- (1966). Obras Completas VI: Poesía. Edición de Manuel García Blanco. Escelicer: Madrid. 
VILLANUEVA, D (1994). Prólogo a CARTELLE MONTERO, Enrique y HERRERO INGELMO, María de la Cruz. De Virgilio a Umberto Eco. Ediciones del Orto-Universidad de Huelva: Madrid.

YOURCENAR, M. (1958). Présentation critique de Constantine Cavafis. Gallimard: París. 